\title{
RESEARCH
}

\section{Sexually dimorphic gene expression and neurite sensitivity to estradiol in fetal arcuate Kiss1 cells}

\author{
Caroline Alfaia1, Vincent Robert1, Kevin Poissenot'1, Yves Levern², Daniel Guillaume1, Shel-Hwa Yeo³, \\ William H Colledge ${ }^{3}$ and Isabelle Franceschini ${ }^{1}$
}

1PRC, INRA, CNRS, IFCE, Tours University, Nouzilly, France

2ISP, INRA, Tours University, Nouzilly, France

3Reproductive Physiology Group, Department of Physiology, Development and Neuroscience, University of Cambridge, Cambridge, UK

Correspondence should be addressed to I Franceschini: isabelle.franceschini-laurent@inra.fr

\begin{abstract}
Kiss1 neurons of the arcuate (ARC) nucleus form an interconnected network of cells that communicate via neurokinin B (encoded by Tac2) and its receptor (encoded by Tacr3) and play key roles in the control of the reproductive axis through sex hormoneregulated synthesis and release of kisspeptin peptides (Kp, encoded by Kiss 1 ). The aim of this study was to determine whether the Kiss 1 cell population of the ARC already displays sexually dimorphic features at embryonic age E16.5 in mice. At this time of development, Kiss1-GFP- and Kp-immunoreactive cell bodies were restricted to the ARC and not found in the pre-optic area (POA). The Kiss1-GFP cell population was identical in size between sexes but had significantly lower Kiss1, Tac2, and Tacr3 mRNA levels and lower $\mathrm{Kp}$-ir fiber density in the POA in male compared to female fetuses. Receptors for androgen (Ar) and estrogen (Esr1, Esr2, Gpr30) and the Cyp19a1 gene (encoding the estradiol-producing enzyme aromatase) transcripts were also detected in fetal ARC Kiss1-GFP cells with significant sex differences for Ar (higher in males) and Esr1 (higher in females). Functional studies on primary cultures of sorted fetal Kiss1-GFP cells revealed a significant negative effect of estradiol treatment on neurite outgrowth on the fourth day of culture in the female group specifically. We conclude that the ARC Kiss 1 cell population is already sexually differentiated at E16.5 and that its morphogenetic development may be particularly vulnerable to estradiol exposure at this early developmental time.
\end{abstract}
Key Words
- kisspeptin neurons
- estradiol
- fetal development
- sexual differentiation
- arcuate nucleus
- morphogenesis

\section{Introduction}

Kisspeptins (Kp), encoded by the Kiss1 gene, are short peptides best known to act in the brain as activators of the reproductive axis at puberty via their potent gonadotrophin-releasing hormone $(\mathrm{GnRH})$ secretagogue activity. Noteworthy, they also play neuromodulatory roles on other neuronal populations throughout the brain (Liu \& Herbison 2016). Kp are produced by two main populations of Kiss1 neurons, the cell bodies of which are located in the preoptic area (POA) including the anteroventral periventricular (AVPV) region, and in the arcuate nucleus (ARC) of the hypothalamus with fibers projecting widely throughout the brain (Lehman et al. 2013).

The Kiss 1 cell population in the POA is larger in females than in males and plays a determinant role in triggering ovulation (Clarkson \& Herbison 2009). 
In the adult ARC, sex differences in Kiss 1 expression are more subtle than in the POA and only apparent using sensitive techniques such as qRT-PCR (Adachi et al. 2007, Knoll et al. 2013). In addition, sex differences in the Kiss1 cell population in the ARC have occasionally been reported at the morphological (Yip et al. 2015) and functional levels in adult mice (De Croft et al. 2012). This sexual dimorphism may be related to the regulatory role some ARC neurons seem to play in the timing of puberty and the cyclic regulation of GnRH pulses and surges in females (Beale et al. 2014, Hu et al. 2015, Mittelman-Smith et al. 2016).

In this study, we hypothesized that the sexual dimorphism of Kiss1 neurons in the ARC starts to develop before birth. It was recently shown that Kiss 1 expression in the ARC is turned on very early in the fetal brain (Desroziers et al. 2012, Knoll et al. 2013). It was therefore possible to isolate ARC Kiss1 cells by FACS from transgenic fetuses expressing GFP under the control of the endogenous Kiss1 promoter. Significant transcriptional and morphological sex differences were found in this cell population at E16.5. The discovery of higher levels of Esr1 in the ARC Kiss 1 cells of female fetuses prompted us to compare the direct estradiol responsiveness of ARC Kiss1 cells in vitro specifically sorted from male and female fetuses.

\section{Materials and methods}

\section{Animals}

Kiss1-CreGFP mice (Gottsch et al. 2011) were obtained from the Jackson Laboratory (Kiss-1 ${ }^{\text {tm1.1(Cre/EGFP)Stei/J; }}$ strain (129S6/SvEvTac x C57BL/6NCr)F1) and bred for over ten generations with C57/B16 mice (Charles Rivers). Mice were housed and bred in the INRA rodent facility of Nouzilly (UEPAO, authorization \# A37801 from the French ministry of agriculture), in compliance with French and European legislation governing the care and use of laboratory animals (Decree 2013-118 du 1er février 2013; Art. R.214-87-88-89 and Decree 2010/63/UE). Age-matched heterozygous embryos were obtained by mating wild type C57/B16 females with homozygous Kiss1-CreGFP males for $4 \mathrm{~h}$ to overnight. The following morning was considered embryonic day E0.5. Kiss1knockout mice (d'Anglemont de Tassigny et al. 2007) and their corresponding wild-type (WT) controls were group housed and bred at the University of Cambridge. Animal handling was carried out with the approval of the Cambridge University Biomedical Services Local Ethics Committee.

\section{Experiment 1: Immunohistochemical} characterization of the ARC Kiss1-GFP cell population

\section{Tissue preparation for immunohistochemistry}

Timed-pregnant mice were killed by cervical dislocation. E16.5 embryos were removed individually by cesarean section. A sample of fetal tissue was collected from each fetus and processed for PCR sexing using primers for Sry (5'-ATGGAGGGCCATGTCAAG-3' and 5'-AACAGGCTGCCAATAAAAGC-3'). The heads were fixed for $24 \mathrm{~h}$ at $4^{\circ} \mathrm{C}$ in $4 \%$ paraformaldehyde in $0.1 \mathrm{M}$ phosphate buffer solution, pH 7.4 (PBS), cryoprotected in a $30 \%$ sucrose solution and stored at $4^{\circ} \mathrm{C}$. Embryonic heads were cut with a cryostat (CM3050S; Leica Microsystems SAS) in the horizontal plane. The ventral forebrain was collected as one set of approximately 80 consecutive 20- $\mu \mathrm{m}$ thick sections that were mounted on gelatin-coated glass slides. The first, most posterior forebrain section collected comprised the interpeduncular fossa and the olfactory bulbs and the last one the median eminence. The slides were stored at $-20^{\circ} \mathrm{C}$ until the immunohistochemistry procedure.

\section{Immunohistochemistry}

Slides from all fetuses were processed at the same time using standard immunofluorescent staining procedure with antibodies listed in Table 1. Following counterstaining with Hoechst 33258 (Invitrogen), slides were dipped in a solution of Sudan black 0.3\% (Sigma-Aldrich), cover-slipped with Fluoromount-G (SouthernBiotech, Birmingham, AL, USA) and stored at $4^{\circ} \mathrm{C}$ in the dark until analysis. The specificity of the staining with the anti-GFP antibody was verified on parallel sections from WT embryos. The specificity of the staining with anti-Kp was verified on parallel sections from Kiss $1 \mathrm{KO}$ embryos or after preadsorbtion of the primary antibody with synthetic Kp52 as previously described (Franceschini et al. 2013).

\section{Fluorescence microscopy and image acquisitions}

All sections were screened for the presence of GFPimmunofluorescent cells using a light microscope (Axio Imager M.2, Carl Zeiss, EC Plan-Neofluar 10×/0.3). The GFP in the transgenic model used is fused to CRE which has a nuclear localization signal. The nuclear localization of the GFP signal, was verified by Hoechst colocalization using higher resolution objectives (EC Plan-Neofluar $20 \times / 0.50$ and EC Plan-Neofluar $40 \times / 0.75$ ). The anatomical position of the GFP-ir cells was recorded according to an atlas of the developing mouse brain (Schambra 2008). 
Table 1 Antibody information.

\begin{tabular}{|c|c|c|c|c|c|}
\hline Peptide/protein target & Antigen sequence (if known) & $\begin{array}{c}\text { Name or cat no. } \\
\text { of antibody }\end{array}$ & Manufacturer source & $\begin{array}{l}\text { Host species } \\
\text { monoclonal or } \\
\text { polyclonal }\end{array}$ & $\begin{array}{c}\text { Dilution } \\
\text { used }\end{array}$ \\
\hline Green fluorescent protein & & GFP1020 & AVES LAB & Chicken polyclonal & 10,000 \\
\hline Kisspeptin & PPVEGPAGRQRPLC & AC053 & Alain Caraty INRA & Sheep polyclonal & 2000 \\
\hline Chicken IgG & & $703-545-155$ & $\begin{array}{l}\text { Jackson } \\
\text { Immunoresearch }\end{array}$ & Donkey polyclonal & 500 \\
\hline Sheep IgG & & 713-066-147 & $\begin{array}{l}\text { Jackson } \\
\text { Immunoresearch }\end{array}$ & Donkey polyclonal & 500 \\
\hline
\end{tabular}

Quantitative analysis of GFP/Kp double immunoreactivity in the ARC and of Kp immunoreactivity in the POA were performed on digital images acquired with a spectral LSM780 confocal microscope (Axio Observer Z1, Carl Zeiss, Plan-Apochromat 40×/1.4 Oil DIC M27) on three representative sections sampled throughout the anteroposterior extent of the ARC and on two representative sections sampled at the level of the highest density of $\mathrm{Kp}$-ir fibers in the medial preoptic area, respectively. The Cy3 signal was captured with a specific $560 \mathrm{~nm}$ emission filter to reduce noise, enabling unambiguous detection of Kp-ir fibres. On each section through the ARC, one image (x: $103.78 \mu \mathrm{m}, \mathrm{y}: 103.78 \mu \mathrm{m} ; 500 \times 500 \mathrm{px}$ ), including at least 12 GFP-ir cells, was acquired (pinhole open to 0.53 DU), at the xyz level of maximum GFP immunoreactivity. Kiss1-GFP cells were considered to be double-labeled $\mathrm{Kp}$ when at least two adjacent pixels with gray value above background were recorded for each fluorochrome. On each section through the POA, two images (x: $212.34 \mu \mathrm{m}, \mathrm{y}: 212.34 \mu \mathrm{m} ; 1024 \times 1024 \mathrm{px}$ ) were acquired (pinhole open to $0.53 \mathrm{DU})$, at the xyz level of maximum Kp immunoreactivity, located $600 \mu \mathrm{m}$ lateral to the third ventricle border and $200 \mu \mathrm{m}$ caudal to the rostral limit of the forebrain. Images were binarized after gray level value thresholding over background and the total pixel number was calculated using ImageJ and used as an estimate of Kp-ir fiber density.

\section{Quantitative analysis}

One male and one female fetus from each of the three different pregnant mice were used for quantitative analysis. The percentage of GFP/Kp double-immunoreactive cells was calculated as the total number of double-labeled cells over the total number of Kiss1-GFP-ir cells. Kp-ir fiber density in the POA was analyzed by variance analysis after logarithmic transformation of the data, with a model totally nested using the procedure PROC NESTED in SAS software (SAS Institute Inc.). The model includes the maternal effect and the sex of the fetuses' effect. The effect of the sex of the fetuses was tested with the data from four acquisition fields per fetus on three malefemale siblings. Results were reported as arithmetical means \pm s.e.M. Statistical differences were considered significant at $P<0.05$.

\section{Fetal MBH cell dissociation and} fluorescence-activated cell sorting (FACS) of Kiss1-GFP cells (experiments 2 and 3 )

E16.5 fetuses were quickly collected and morphologically sexed by macroscopic examination of their gonads. Brains were removed and placed with the ventral surface upward in a small petri dish under a stereomicroscope. A small tissue block including the mediobasal hypothalamus $(\mathrm{MBH})$ was delimited by two lateral cuts lying approximately $350 \mu \mathrm{m}$ to either side of the midline and one rostral cut behind the optic chiasma using ophthalmic scissors and dissected out with fine curved forceps inserted in the mesencephalic flexure. Depending on the success of overnight matings, two to four pregnant mice were obtained per experiment, and the dissected $\mathrm{MBH}$ tissues from all fetuses (originating from the different pregnant mice) were pooled and grouped according to sex prior to cell dissociation and FACS sorting. For cell dissociation, these tissues were briefly chopped with a $\mathrm{n}^{\circ} 10$ scalpel blade before enzymatic digestion in a solution of papain and DNase (Worthington, Lakewood, NJ, USA). Cells were mechanically dissociated via passages through $30 \mathrm{G}$ and $27 \mathrm{G}$ needles and centrifuged. The pellet was resuspended in a solution of albumin/ovomucoid (1 $\mathrm{mg} / \mathrm{mL}$ in EBSS buffer) and filtered through $40 \mu \mathrm{m}$ nylon mesh. Cells were centrifuged at $300 \boldsymbol{g}$ for 5 min over a cushion of albumin/ovomucoid (10 $\mathrm{mg} / \mathrm{mL}$ in EBSS) and resuspended in phenol red-free neurobasal medium supplemented with 2\% B-27 (Invitrogen), 1\% Glutamax (Gibco) and $10 \mu \mathrm{g} / \mathrm{mL}$ Gentamycin (Sigma-Aldrich). Cell suspensions were maintained on ice until FACS followed by qRT-PCR analysis or cell culture. Dissociated $\mathrm{MBH}$ cells were sorted on MoFlo® Legacy or Astria cell sorters (Beckman Coulter), using a blue laser operating at $488 \mathrm{~nm}$. Cells were sorted with 90-100 $\mu \mathrm{m}$ nozzles based on 
positive fluorescence in the green channel using precisely the same gating parameters for the male and female group of cells. Debris was eliminated based on morphological criteria using forward scatter (FSC) vs side scatter (SSC). The position of the sort window for Kiss1-GFP-positive cells was evaluated by comparison with WT mouse green auto-fluorescence.

\section{Experiment 2: Transcriptional characterization of the ARC Kiss1-GFP cell population}

\section{Quantitative RT-PCR (qRT-PCR)}

For each FACS experiment, 500 cells of each group were directly collected in a PCR tube filled with $9 \mu \mathrm{L}$ of lysis reagent and stored on ice until RT in the same tube as previously described (Ho et al. 2013). Quantitative PCR was performed with a qPCR iCycler (iQV3.1 software; BioRad) using Sso advanced SYBR Green Supermix (BioRad). PCR cycling conditions were optimized from previously published protocols using the primers listed in Table 2 . The PCR cycle for Ar, Tacr3, Esr1 and Esr2 consisted of a 5 -min denaturation step at $95^{\circ} \mathrm{C}$, followed by 40 rounds of amplification defined by $10-15 \mathrm{~s}$ denaturation at $95^{\circ} \mathrm{C}, 59 \mathrm{~s}$ annealing at $55.5-61^{\circ} \mathrm{C}$ depending on the target, and $10 \mathrm{~s}$ extension at $72^{\circ} \mathrm{C}(2 \mathrm{~s}$ for Tacr3). For Actbh, Polr2a, Kiss1, Tac2, Cyp19a1 and Gpr30, PCR samples were first heated $2 \mathrm{~min}$ at $50^{\circ} \mathrm{C}$ and 5 to $10 \mathrm{~min}$ at $95^{\circ} \mathrm{C}$, followed by 40 cycles of amplification defined by $10-15 \mathrm{~s}$ at $95^{\circ} \mathrm{C}$ and 59 $s$ at $60^{\circ} \mathrm{C}$ (Polr2a, Cyp19a1 and Gpr30) or $60.7^{\circ} \mathrm{C}$ (Actbh, Kiss1, Tac2). PCR specificity was verified by melting curve analysis and agarose gel electrophoresis. Each sample was run in triplicate to obtain an average cycle threshold value (Ct). Negative control samples devoid of cDNA templates were included for each PCR and yielded no amplification. For each assay, a standard curve was created using a serial dilution of cDNA from a pool of Kiss1-GFP sorted cells or from punches of postnatal ARC. PCR efficiencies ranged from 80 to $105 \%$ depending on the target gene. A cycle threshold (Ct)-based relative quantification with efficiency correction and normalization to two housekeeping genes (Actb and Polr2a) was calculated using the software Bio-Rad CFX Manager 3.0.

\section{Statistical analysis}

Five independent FACS experiments were included in the analysis of the average number of GFP cells sorted per fetus and gene expression analysis by qRT-PCR. All data are expressed as the mean \pm S.E.M. and represented by histograms. Statistical analysis was performed using GraphPad Prism version 5.00 for Windows. Two sample comparisons were performed using paired Wilcoxon or Mann-Whitney tests. Statistical differences were considered significant at $P<0.05$.

\section{Experiment 3: Primary culture of ARC Kiss1-GFP cells}

\section{Primary cell culture}

FACS sorted cells were collected into $500 \mu \mathrm{L}$ Eppendorf tubes filled with phenol red-free neurobasal medium

Table 2 Primer information.

\begin{tabular}{|c|c|c|c|}
\hline \multirow{3}{*}{$\begin{array}{l}\text { Target gene } \\
\text { Beta actin }(A c t b)\end{array}$} & \multicolumn{2}{|c|}{ Primer sequence } & \multirow{2}{*}{$\begin{array}{c}\text { Amplicon (bp) } \\
159\end{array}$} \\
\hline & Fwd & TGACCCAGATCATGTTTGAG & \\
\hline & Rev & GGAGAGCATAGCCCTCGTAG & \\
\hline \multirow[t]{2}{*}{ Polypeptide A (Polr2a) } & Fwd & GCACCACGTCCAATGATAT & 267 \\
\hline & Rev & GTGCTGCTGCTTCCATAA & \\
\hline \multirow[t]{2}{*}{ Kisspeptin (Kiss1) } & Fwd & AGCTGCTGCTTCTCCTCTGT & 118 \\
\hline & Rev & GATTCCTTTTCCCAGGCATT & \\
\hline \multirow[t]{2}{*}{ Neurokinin B (Tac2) } & Fwd & TTCCACAGAAACGTGACATGC & 101 \\
\hline & Rev & GGGGGTGTTCTCTTCAACCAC & \\
\hline \multirow[t]{2}{*}{ Tachykinin receptor 3 (Tacr3) } & Fwd & CCAACTACTGCCGCTTCCA & 272 \\
\hline & Rev & GAAATGTTGCTTGGGACCTTCT & \\
\hline \multirow[t]{2}{*}{ Estrogen receptor alpha (Esr1) } & Fwd & CGTGTGCAATGACTATGCCTCT & 128 \\
\hline & Rev & TGGTGCATTGGTTTGTAGCTGG & \\
\hline \multirow[t]{2}{*}{ Androgen receptor (Ar) } & Fwd & GGCGGTCCTTCACTAATGTCAACT & 142 \\
\hline & Rev & TGGAGCCATCCAAACTCTTGAGAC & \\
\hline \multirow[t]{2}{*}{ Cytochrome P450 (Cyp19a1) } & Fwd & TGTGTTGACCCTCATGAGACA & 190 \\
\hline & Rev & CTTGACGGATCGTTCATACTTTC & \\
\hline \multirow[t]{2}{*}{ Estrogen receptor beta (Esr2) } & Fwd & GTCAGGCACATCAGTAACAAGGG & 96 \\
\hline & Rev & ATTCAGCATCTCCAGCAGCAGGTC & \\
\hline \multirow[t]{2}{*}{ G-protein-coupled estrogen receptor 1 (Gpr30) } & Fwd & GTGGCCAAGCCTCAACACTCAC & 103 \\
\hline & Rev & GGTGGACAGGGTGTCTGATGTCTG & \\
\hline
\end{tabular}


supplemented with 2\% B-27, 1\% Glutamax (Gibco), $10 \mu \mathrm{g} / \mathrm{mL}$ Gentamycin (Sigma-Aldricht), 10\% charcoalstripped FBS and 20 ng/mL FGF2 (PreproTech). Cells were seeded on poly-ornithine-laminin-coated glass multi-well slides (Lab-tek chamber slide system, 8 wells, Nunc) at a density of 300 cells in $30 \mu \mathrm{L}$ at the center of each well and allowed to settle for $2 \mathrm{~h}$ in a $37^{\circ} \mathrm{C}, 5 \% \mathrm{CO}_{2}$ incubator. $300 \mu \mathrm{L}$ of the same medium were then added to each well. Twenty-four hours after seeding, the entire medium was replaced by FBS-free medium with or without $100 \mathrm{pM}$ 17 - $\beta$-estradiol ( $\mathrm{E}_{2}$, Sigma-Aldrich).

\section{Time-lapse recording}

From 2 to 4 days in culture (DIV), cells were incubated under a LSM780 confocal microscope (Axio Observer Z1, Carl Zeiss) equipped with a culture chamber at $37^{\circ} \mathrm{C}$ in $5 \% \mathrm{CO}_{2}$. Digital image tiles of each well were recorded in transillumination every $6 \mathrm{~h}$ using a $\times 20$ objective (PlanNeofluar 20×/0.50 M27).

\section{Morphological analysis}

Operators were blind to treatment or sex, all refractive cells were manually counted on images recorded 25, 55 and $85 \mathrm{~h}$ after cell seeding (DIV2, DIV3 and DIV4, respectively) using the cell counter plug-in of Image (NIH). Neurite lengths were manually measured using the segmented line measurement of ImageJ. Neurons contacting each other or bypassing the acquisition field were excluded from the analysis.

\section{Statistical analysis}

Five independent FACS/primary culture experiments were included in the analysis of the average number of GFP cells detected per fetus and of the number of adherent cells at DIV2. Two sample comparisons between male and female were performed using paired Wilcoxon and MannWhitney tests with GraphPad Prism, version 5.00 for Windows. Three experiments were followed by time lapse from DIV2 to DIV4. For each culture, experimental group and timepoint, neurites from all distinct neurite-bearing cells were measured. Multiple comparisons between time, sex and treatment groups were performed using threefactor repeated-measures ANOVA on Statistica, version 10.00 with sex and treatment as independent factors. When applicable, Fisher's least significant difference post hoc comparisons were used to determine statistical differences between groups of interest. All data are expressed as the mean \pm S.E.M. and represented by histograms. Statistical differences were considered significant at $P<0.05$.

\section{Results}

\section{Experiment 1: Similar GFP and Kp immunoreactivity in the ARC of male and female fetuses but higher Kp-ir fiber density in the POA of female fetuses}

Kiss1-GFP-ir cells were distributed along the entire anteroposterior extent of the fetal ARC, positioned bilaterally on the ventral sides of the third ventricle, from the level of the infundibular recess to the mammillary recess in both male and female fetuses (Fig. 1A). Counterstaining with Hoechst enabled verification that the GFP protein which carries a nuclear localization sequence was confined to cell nuclei. Kiss1-GFP neurons were not found in the other ventral forebrain areas where Kiss 1 expression has been described in adults including the POA, dorsomedial nucleus and medial amygdala. The majority of Kiss1-GFP cells were concentrated in a small ARC area just above the developing pituitary. Their density appeared similar between males and females (Fig. 1B and C). In female and male fetuses, the majority of the $\mathrm{GFP}^{+}$cells also expressed $\mathrm{Kp}(80 \pm 8 \%$ in females and $81 \pm 8 \%$ in males; Fig. $1 \mathrm{~B}$ and $\mathrm{C}$ respectively). The specificity of the $\mathrm{Kp}$ immunolabeling was confirmed by the absence of staining in the ARC of age-matched Kiss1 KO fetuses, in contrast to the clear Kp immunofluorescent signal detected in the ARC of WT counterparts (data not shown). Scattered Kp-ir fibers were detected in the lateral and medial POA of both male and female fetuses, where these appeared to concentrate in a small region anterior to the preoptic nucleus and ventral to the bed nucleus of the stria terminalis (Fig. $1 \mathrm{~A}^{\prime}$ ). There was no significant maternal effect, but there was a significant effect of fetal sex on Kp-ir density which was on average two-fold higher in female than male fetuses at this stage of pregnancy ( $P=0.018$, Fig. 1D, E and F).

\section{Experiment 2: Sex differences in the transcriptional profile of E16.5 ARC Kiss1-GFP cells}

This experiment was designed to investigate the possible sex differences in the transcriptional profile of the Kiss1-GFP cell population of the fetal ARC at the time of the male-specific prenatal (E16.5) testosterone surge. We focused on transcripts playing key roles in the maturation of reproductive function and previously identified in adult ARC Kiss1 cells. These included Kiss1, Tac2, Esr1 and $A r$. Figure 2A displays the position of the sort window for Kiss1-GFP-positive cells, which was set by comparison with WT mouse green auto-fluorescence (Fig. 2B). 


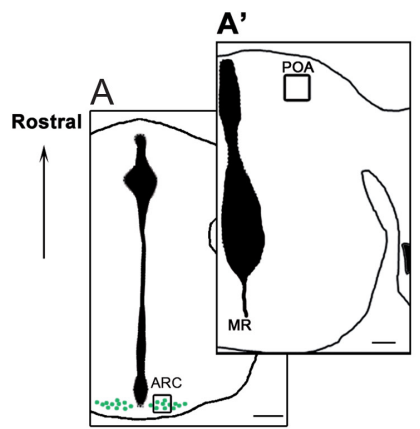

B
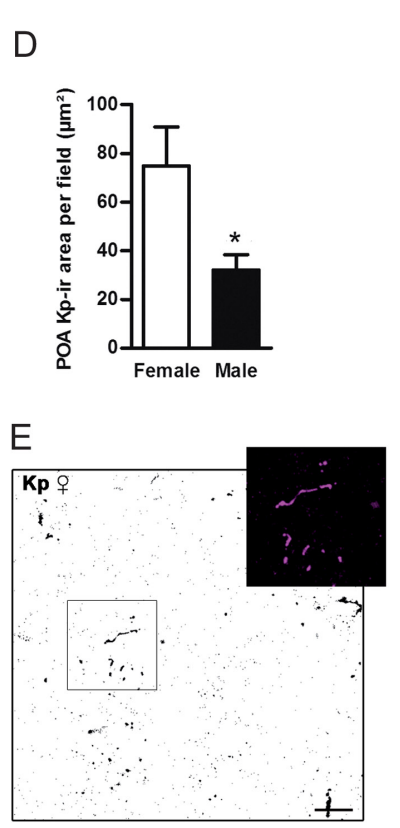

C
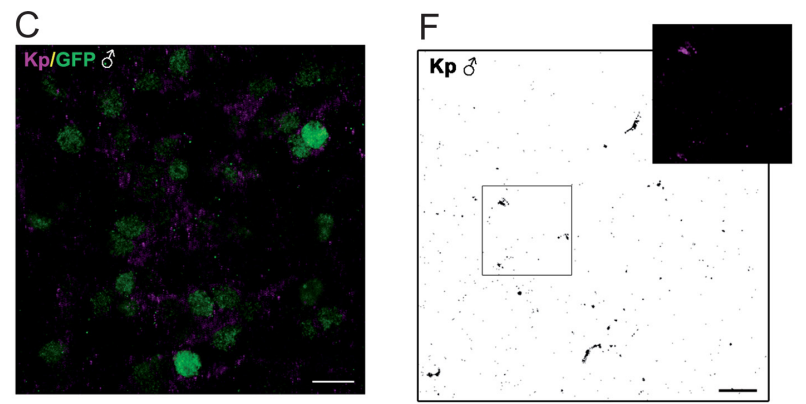

Figure 1

GFP and Kp immunoreactivity in the ARC and rostral POA of E16.5 male and female brains. Schematic drawings of two horizontal sections through the ventral forebrain at the level of the arcuate nucleus $(A)$ and preoptic area $\left(A^{\prime}\right)$, illustrating the restricted localization of Kiss1-GFP cells in the ARC. (B and C) Representative confocal optical sections scanned at the level of the boxed area in (A), illustrating Kp (magenta) and GFP (green) immunoreactivity in the arcuate nucleus of a female and male brain respectively. Note that the density of GFP-immunoreactive cell nuclei was undistinguishable between males and females and that most were apposed to $\mathrm{Kp}$ immunoreactivity in males as in females. (D) Quantitative analysis (mean \pm S.E.M. of Kp immunoreactive surface area per field in the area of the POA illustrated by the squared box in $A^{\prime}$. Nested ANOVA detected a significant effect of $\operatorname{sex}^{*}{ }^{*} P<0.05$. (E and F) Representative binarized confocal optical sections scanned at the level of the boxed area in $\left(A^{\prime}\right)$, illustrating $\mathrm{Kp}$ (black) immunoreactivity in the rostral POA of female (E) and male (F) fetuses. A representative illustration of Kp-immunofluorescent fibers (magenta) is displayed in the top right corner of each binarized image. The lateral and third ventricle are filled in black. Arc, arcuate nucleus; MR, mammillary recess; POA, preoptic area. Scale bars: $200 \mu \mathrm{m}$ ( $A$ and $A^{\prime}$ ); $20 \mu \mathrm{m}(B) ; 10 \mu \mathrm{m}$ (D and $\left.E\right)$.

The average number of GFP+ sorted cells per ARC was not statistically different between male and female fetuses (female $170 \pm 41.7$ and male $175.3 \pm 36.4 \mathrm{GFP}+$ cells per ARC, $P=0.63$ ) consistent with our IHC data. Kiss1 mRNA levels were significantly enriched in the population of
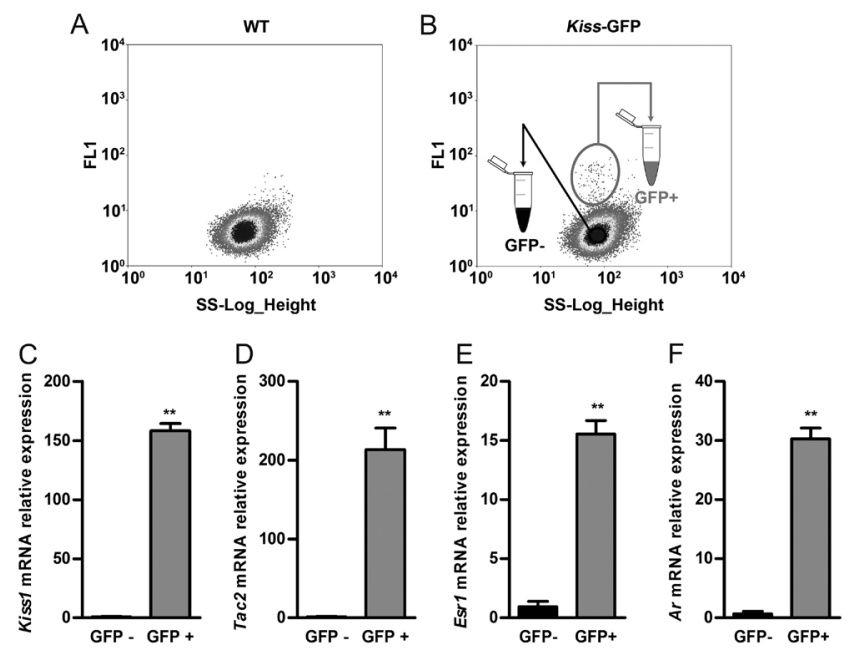

Figure 2

Enrichment in Kiss1, Tac2, Esr1 and Ar transcripts in Kiss1-GFP cells sorted from E16.5 ARC. Representative FACS profiles (FL1/SSC) from a pool of wild type (A) and Kiss1-GFP (B) fetal MBH cell suspension, displaying in $B$ the sort windows for GFP- (black circle) and GFP+ (gray circle) cells. The specificity of the GFP+ sort window in B is attested by the absence of events in this area in A. Histograms display quantitative analysis of Kiss1 (C), Tac2 (D), Esr1 (E) and Ar (F) mRNA levels as measured in the sorted cell populations by RT-qPCR (mean \pm S.E.M). Data are expressed as fold change in relative expression with GFP- cell sorts arbitrary set at 1. All transcripts were significantly enriched in GFP+ cells as compared to GFP cells. MannWhitney test, $* * P<0.01$.

$\mathrm{GFP}^{+}$sorted cells compared to the GFP- sorted one (150fold higher, $P<0.01$ ) (Fig. $2 \mathrm{C}$ ). $\mathrm{GFP}^{+}$sorted cells also expressed 200-fold more Tac2 transcripts $(P<0.01)$ (Fig. 2D), 15-fold more Esr1 transcripts $(P<0.01)$ (Fig. 2E) and 30-fold more $A r$ transcripts $(P<0.01)$ than the GFPcells (Fig. 2F). Significant sex differences were detected among the GFP+ sorted cells: Kiss1, Tac2 and Tacr3 mRNA levels were significantly lower in the male compared to the female Kiss1-GFP cell population $(P<0.05)$ (Fig. 3A, $\mathrm{B}$ and $\mathrm{C}$ respectively). Significant sex differences were also detected in Esr1 and $A r$ transcript levels, which were respectively lower and higher in the male compared to the female Kiss1-GFP cell population $(P<0.05)$ (Fig. 3D and E respectively). Gpr30, encoding a membrane anchored GPCR estrogen receptor, and Esr2, encoding estrogen receptor beta and Cyp19a1, encoding aromatase, were detected in male and female GFP-sorted cells but could not be quantitatively compared between sexes due to low detection levels (data not shown).

\section{Experiment 3: Morphogenetic response of cultured Kiss1-GFP neurons to estradiol}

The differences observed in the level of Esr1 expression between the male and female Kiss1-GFP cell populations 

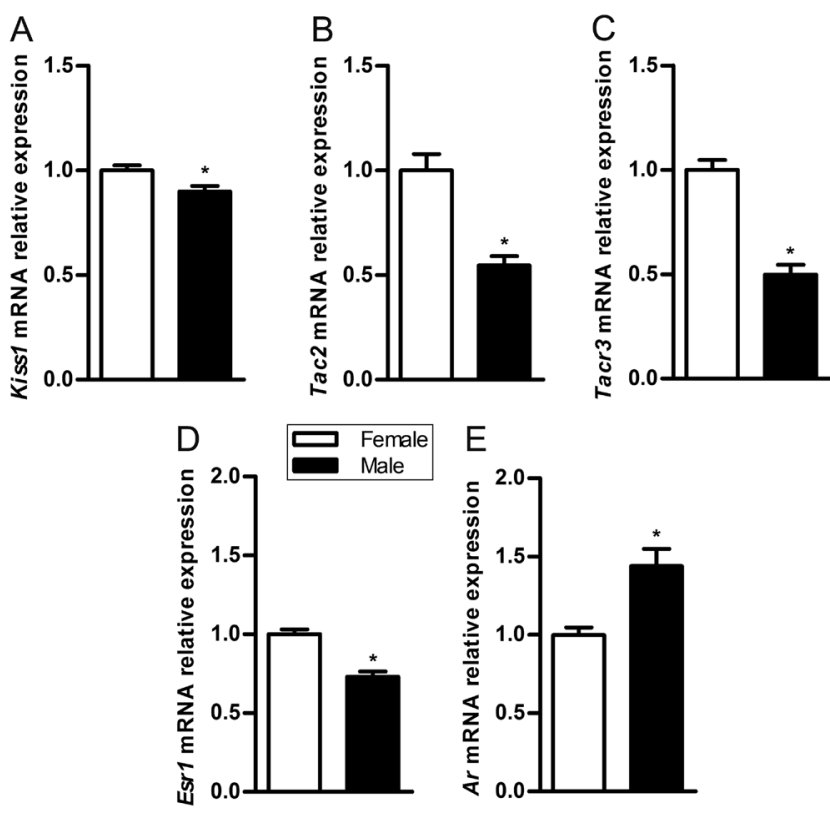

\section{Figure 3}

Sex differences in Kiss1, Tac2, Tacr3, Esr1 and Ar mRNA levels in Kiss1-GFP cells sorted from E16.5 ARC. Histograms display quantitative analysis of Kiss1 (A), Tac2 (B), Tacr3 (C), Esr1 (D) and Ar (E) relative mRNA levels in sorted Kiss1-GFP cells as measured by RT-qPCR (mean \pm S.E.M., expressed as fold change in relative expression with values for Kiss1-GFP cells sorted from the female ARC arbitrary set at 1). Mann-Whitney tests revealed significant sex differences for each transcript, with females expressing higher levels of Kiss1, Tac2, Tacr3 and Esr1 and lower levels of Ar than their male siblings. Mann-Whitney test, $* P<0.05$.

(Experiment 2) suggested that the response of this cell population to estradiol could differ between sexes at this early developmental stage. During fetal development, estradiol is known to influence neuronal survival and axonal growth in different cell populations (McCarthy 2008). Since these effects can conveniently be studied in vitro (de Lacalle 2006), we developed a culture system where FACS sorted Kiss1-GFP cells grew neurites for several days in vitro (Fig. 4A, B and C). This enabled investigation of estradiol's morphogenetic effects on this parameter. The average number of GFP+-sorted cells per fetal $\mathrm{MBH}$ was not statistically different between sexes (female $354.6 \pm 42.7$ and male $347.8 \pm 39.87$ GFP+ cells per ARC; $P=0.81)$. A significant sex difference was detected in the number of healthy adhered cells per well at 2 days of culture (DIV2) $(P<0.05)$ (Fig. 4D). The mean cell density was $9 \pm 1$ cells $/ \mathrm{mm}^{2}$ in female and $11 \pm 1$ cells $/ \mathrm{mm}^{2}$ in male cultures. For all experimental groups, the majority of surviving neurons extended one single neurite. Neurites generally grew along non-linear routes as illustrated in Fig. 4C and sometimes contacted each other by the fourth day.
Three-way ANOVA detected a significant effect of time on neurite initiation but did not detect any effect of treatment nor sex on this parameter (Fig. 4E). Post hoc analysis revealed a significant increase in the number of cells with neurites between DIV2 and DIV3 in the female groups regardless of treatment and in the untreated male group (Fig. 4E). The number of cells with primary neurites remained stable between DIV3 and DIV4 for all experimental conditions. Three-way ANOVA detected a significant increase of neurite length with time $(P<0.001)$ and an interaction of time with treatment $(P<0.05)$ (Fig. $4 \mathrm{~F})$. At DIV4, estradiol-treated female cultures had significantly shorter neurites than their control counterpart $(P=0.02)$. Estradiol-treated male cultures also displayed on average shorter neurites than controls but the difference did not reach statistical significance $(P=0.28)$.

\section{Discussion}

This is the first study to show that Kiss1 neurons in the ARC region of the hypothalamus show clear sexual dimorphisms at E16.5 of fetal development, in terms of transcription of major genes important for reproduction, morphology and in vitro direct morphogenetic response to estradiol.

Immunohistochemical analysis of the ventral forebrain did not detect any Kiss1-GFP neurons anywhere other than the ARC at this fetal stage, even after immunohistochemical amplification of the GFP signal. This is consistent with previous reports using in situ hybridization or other mice lines reporting Kiss1 promoter activity to map Kiss1 cells in fetal brains (Knoll et al. 2013, Kumar et al. 2014, 2015). In addition, 80\% of the GFP+ cells also expressed $\mathrm{Kp}$ for both sexes. We are therefore confident that fluorescence-activated cell sorting of the GFP+ cells isolated predominantly the Kiss1 neurons of the ARC. The efficiency of this sorting procedure was attested by the 150-fold enrichment in Kiss 1 transcripts in the GFP+ fraction of cells. We provide here the first evidence that fetal ARC Kiss1 cell population already co-expresses Tac2 and Tacr3, which is very early compared to other cell populations of the $\mathrm{MBH}$. There is evidence for an autocrine/paracrine communication between ARC Kiss1 neurons via neurokinin B in adults (Navarro et al. 2009, Krajewski et al. 2010). It is therefore conceivable that some ARC Kiss1 neurons already communicate locally via neurokinin $B$ in the fetal brain and that this 

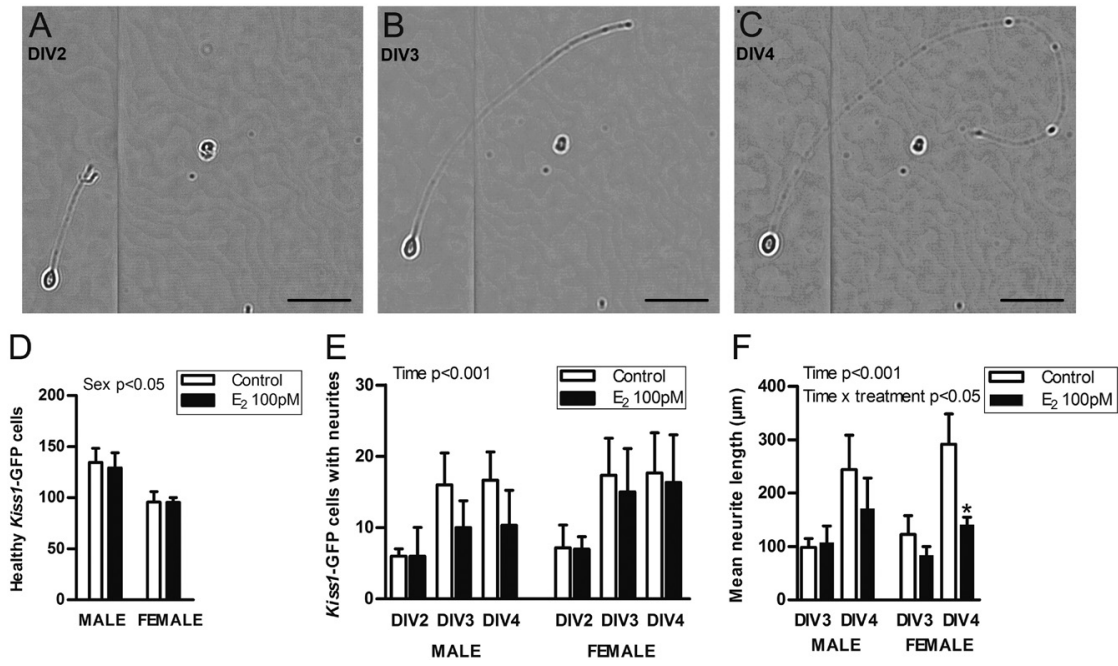

\section{Figure 4}

Morphogenetic effects of estradiol on primary cultures of ARC Kiss1-GFP cells sorted from male and female E16.5 ARC. Bright field photomicrographs of a sorted cell on the second (DIV2, A), third (DIV3, B) and fourth day in vitro (DIV4, C), illustrating neurite outgrowth. (D) Quantitative analysis of the number of healthy adhered Kiss1-GFP cells per culture at DIV2 as a function of sex and estradiol (E2, 100 pM) treatment. Two-way ANOVA detected a significant effect of sex on cell survival at DIV2. (E and F) Quantitative analysis of respectively the number of neurite-bearing Kiss1-GFP cells per culture and neurite length, as a function of sex, culture time and E2 treatment. Three-way ANOVA detected a significant effect of culture time on neurite initiation and a significant effect of time and interaction between time and treatment on neurite length. Post hoc Fisher's least significant difference test, $* P<0.05$ compared with control female at DIV4. Scale bar: $10 \mu \mathrm{m}$. communication plays an active role in the early stages of maturation of the reproductive axis (Gianetti et al. 2010).

Significant sex differences among the E16.5 ARC Kiss1-GFP neurons were detected for various parameters. For instance, Kiss1 mRNA levels were 10\% lower in the male population of sorted Kiss1-GFP cells. In contrast, FACS and immunohistochemical analyses were unable to detect any significant sex difference in the average number and density of ARC Kiss1-GFP cell bodies per fetus. This discrepancy is consistent with a previous report (Knoll et al. 2013) and probably reflects the higher sensitivity of qPCR over the quantification of reporter fluorescent molecule or indirect immunohistochemical labeling for gene expression analysis. It implies that the size of the ARC Kiss1 population does not differ between sexes but that Kiss1 mRNA levels per cell are on average lower in male than female fetuses at this developmental stage. This differs from the sexual dimorphism detected a few days later in the fetal POA where the size of the kisspeptin cell population was clearly higher in male than female fetuses (Clarkson et al. 2014). In addition, significant sex differences were detected in the levels of Tac2 and Tacr3 transcripts in the fetal ARC Kiss1 cell population. Both were also lower in the population of Kiss1-GFP cells sorted from male fetuses, suggesting reduced neurokinin B signaling between ARC Kiss1 cells in male compared to female fetuses. The sex differences in the wiring and regulation of ARC neurokinin $B$ cells that have been identified postnatally (Ciofi et al. 2006, Kauffman et al. 2009) may thus have a fetal origin.

In the ARC of adult mice, Kiss1, Tac2 and Tacr3 are under acute downregulation by circulating estradiol and testosterone (Smith et al. 2005a,b, Navarro et al. 2009,

(C) 2020 Society for Endocrinology Published by Bioscientifica Ltd. Printed in Great Britain
2011). However, whether these genes are already regulated by gonadal hormones prior to birth is not yet clear. Genetic studies in mice suggest a role for gonadal factors in the regulation of Kiss1 expression in the MBH of E17 fetuses (Knoll et al. 2013). Interestingly, our gene expression analysis revealed a considerable enrichment of Esr1 and Ar transcripts within ARC Kiss1-GFP cells as compared to the other cell populations of the E16.5 MBH. This result reinforces previous indirect immunohistochemical data that most ARC Kiss1 cells could already synthesize $\mathrm{ER} \alpha$ and AR proteins by E16.5 (Kumar et al. 2014, 2015). Hence, ARC Kiss1 cells may already be a primary direct target of sex steroids in the fetus. In male fetuses, Kiss1, Tac2 and Tacr3 downregulation by sex steroid receptor signaling in the ARC could possibly contribute to a negative feedback regulation by circulating testosterone on LH secretion at the end of fetal life (Pointis et al. 1980). Noteworthy, we also detected significant sex differences in Esr1 and Ar mRNA levels within the sorted Kiss1-GFP cells (being respectively higher and lower in females than males). As described in other embryonic neural cell systems, this sex difference may be the result of an interaction between gonadal hormones, neuronal derived estradiol and sex chromosome complement (Young \& Chang 1998, Cambiasso et al. 2017). As a consequence, the sensitivity and responses of these cells to steroids during early development is likely to differ between males and females. Later in life, a similar sex difference in sex steroid receptor expression appears to develop in the Kiss1 cell population of the POA (Poling et al. 2017).

Beyond their action on gene transcription, sex steroids, in particular, estrogens can also exert important morphogenetic actions on developing brain structures 
(McCarthy 2008). We therefore sought to compare the distribution of ARC Kiss1-GFP neurons and Kp-ir fibers between male and female fetuses. It is unlikely that the Kp-ir fibers detected originated from Kiss1 neurons in regions other than the ARC since there is no evidence for Kiss1 expression elsewhere in the brain at this early fetal stage (Knoll et al. 2013, Kumar et al. 2014, 2015 and present study). A very small amount of Kp-ir cell bodies have been detected in the POA prenatally, but at later fetal stages (Desroziers et al. 2012, Clarkson et al. 2014). Kp-ir fibers were more abundant in females than male fetuses in the POA, despite similar numbers of Kiss1-GFP cells and similar amount of $\mathrm{Kp}$ immunoreactivity in the ARC between sexes, as revealed by FACS analysis and immunohistochemistry. This region of the developing POA, located at the rostrolateral border of the medial preoptic nucleus, appears to correspond to a portion of the medial forebrain bundle (MFB) (Schambra 2008). These fetal Kiss1 fibers may be en route toward various forebrain regions where ARC Kiss1 neurons are known to project in adulthood (Yip et al. 2015). Another research group, using genetically engineered mice with a Tdtomato reporter of Kiss1-cre activity showed the presence of Tdtomato fibers in the POA of female fetuses but not male fetuses, despite similar numbers of Tdtomato cell bodies, restricted to the ARC (Kumar et al. 2014, 2015). Taken together, these results suggest that some ARC Kiss1 neurons already project to the rostral POA during fetal life and are more abundant in females. This adds to the growing list of sexually dimorphic features observed prenatally in this ventral forebrain area (Henderson et al. 1999, Wolfe et al. 2005). These few rostral projections may have been missed in a previous tract-tracing study using DiI on fixed neonatal brains that suggested that ARC projection pathways toward the POA establish postnatally via a predominant periventricular pathway and are not sexually dimorphic (Bouret et al. 2004). The early ARC rostral Kp projections suggested by the present study may correspond to the recently identified ARC neurokinin B fibers mapped in adult rats along the ventral hypothalamic tract and medial forebrain bundle (Krajewski et al. 2010), two fiber tracts which course more laterally and develop prenatally (Altman \& Bayer 1978, Goldsmith \& Song 1987). In summary, results from gene expression analysis on sorted Kiss1-GFP cells and from Kp immunohistochemistry on fetal brains suggest that the ARC population of Kiss1 cells is prenatally wired and directly responsive to androgens and estrogens in a sex-specific way.

We started to investigate this hypothesis by testing the direct morphological responsiveness of these neurons to exposure to a low dose of estradiol (100 pM) in vitro. We successfully set up culture conditions that allowed survival and neurite outgrowth of sorted Kiss1-GFP neurons for several days. This culture system is thus very useful to study morphogenetic effects induced by estradiol on Kiss1 neurons, as opposed to the previously described immortalized Kiss1 cell lines which do not show signs of morphological differentiation in vitro and are rather best suited for molecular investigations (Jacobs et al. 2016, Treen et al. 2016). A significant sex difference, in favor of males, was detected in the number of cells that adhered and survived $24 \mathrm{~h}$ after FACS, adding further evidence of a sex difference in the biological properties of ARC Kiss1 cells in the fetus. How this observation relates to the transcriptional or morphological sex differences observed in vivo remains to be explored. Although ANOVA was not able to detect any significant effect of sex on the neurite outgrowth inhibitory response to $100 \mathrm{pM}$ estradiol, only Kiss 1 cells sorted from female fetuses displayed a significant decrease in neurite outgrowth on the fourth day of culture as compared to their untreated control counterparts (Fisher LSD, $P<0.05$ ). This may be related to the higher expression of Esr1 among the female Kiss 1 cell population. In the same vein, a higher vulnerability of female fetuses to exogeneous estrogenic compounds affecting hypothalamic functions has previously been reported (Rebuli \& Patisaul 2016).

In conclusion, this study demonstrates sex differences in Kiss1, Tac2, Tacr3, Esr1 and Ar mRNA levels within fetal ARC Kiss1 cells and in Kp-ir fiber density in the POA, suggesting that male and female ARC Kiss1 neurons are already differently wired and prone to respond in different ways to sex steroids in the fetus. We developed a primary culture system of purified fetal ARC Kiss1 cells which directly responded to $100 \mathrm{pM}$ estradiol by decreased neurite outgrowth over culture time. Further studies are however needed to fully explore a possible sex effect in this response and to decipher the precise mechanism of action of estrogens on fetal ARC Kiss1 cells.

\section{Declaration of interest}

The authors declare that there is no conflict of interest that could be perceived as prejudicing the impartiality of the research reported.

\section{Funding}

This work was supported by grants from ANR (ANR-15-CE20-0015-01) and BBRC (BB/K003178/). C A was recipient of PhD fellowships from the University of Tours and from the Fondation pour la Recherche Medicale (FDT20160736471). 


\section{Author contribution statement}

$\mathrm{C} \mathrm{A}$ and I F designed the experiments. C A, V R, K P, Y L, and S Y performed experiments. C A, V R, K P, Y L, D G, S-H Y, W H C, and I F analyzed the experiments. $C A$ and I $F$ wrote the paper.

\section{Acknowledgments}

The authors thank Claude Cahier, Déborah Crespin, and Aurélie Sauvage from the UEPAO animal facility for taking care of the animals and Victoria Kyle for tail PCR genotyping of the fetuses. This work has benefited from the facilities and expertise of the 'Plateforme $\mathrm{d}^{\prime}$ Imagerie Cellulaire'/Cell imaging platform (PIC) of the UMR PRC and they are particularly grateful to Marie-Claire Blache for her expert assistance in spectral confocal microscopy, time lapse acquisitions and image analysis.

\section{References}

Adachi S, Yamada S, Takatsu Y, Matsui H, Kinoshita M, Takase K, Sugiura H, Ohtaki T, Matsumoto H, Uenoyama Y, et al. 2007 Involvement of anteroventral periventricular metastin/kisspeptin neurons in estrogen positive feedback action on luteinizing hormone release in female rats. Journal of Reproduction and Development $\mathbf{5 3}$ 367-378. (https://doi.org/10.1262/jrd.18146)

Altman J \& Bayer SA 1978 Development of the diencephalon in the rat. II. Correlation of the embryonic development of the hypothalamus with the time of origin of its neurons. Journal of Comparative Neurology 182 973-993. (https://doi.org/10.1002/cne.901820512)

Beale KE, Kinsey-Jones JS, Gardiner JV, Harrison EK, Thompson EL, Hu MH, Sleeth ML, Sam AH, Greenwood HC, McGavigan AK, et al. 2014 The physiological role of arcuate kisspeptin neurons in the control of reproductive function in female rats. Endocrinology 155 1091-1098. (https://doi.org/10.1210/en.2013-1544)

Bouret SG, Draper SJ \& Simerly RB 2004 Formation of projection pathways from the arcuate nucleus of the hypothalamus to hypothalamic regions implicated in the neural control of feeding behavior in mice. Journal of Neuroscience 24 2797-2805. (https://doi. org/10.1523/JNEUROSCI.5369-03.2004)

Cambiasso MJ, Cisternas CD, Ruiz-Palmero I, Scerbo MJ, Arevalo MA, Azcoitia I \& Garcia-Segura LM 2017 Interaction of sex chromosome complement, gonadal hormones and neuronal steroid synthesis on the sexual differentiation of mammalian neurons. Journal of Neurogenetics 31 300-306. (https://doi.org/10.1080/01677063.2017.1 390572)

Ciofi P, Leroy D \& Tramu G 2006 Sexual dimorphism in the organization of the rat hypothalamic infundibular area. Neuroscience $\mathbf{1 4 1} 1731$ 1745. (https://doi.org/10.1016/j.neuroscience.2006.05.041)

Clarkson J \& Herbison AE 2009 Oestrogen, kisspeptin, GPR54 and the pre-ovulatory luteinising hormone surge. Journal of Neuroendocrinology 21 305-311. (https://doi.org/10.1111/j.1365-2826.2009.01835.x)

Clarkson J, Busby ER, Kirilov M, Schutz G, Sherwood NM \& Herbison AE 2014 Sexual differentiation of the brain requires perinatal kisspeptinGnRH neuron signaling. Journal of Neuroscience 34 15297-15305. (https://doi.org/10.1523/JNEUROSCI.3061-14.2014)

d'Anglemont de Tassigny X, Fagg LA, Dixon JPC, Day K, Leitch HG, Hendrick AG, Zahn D, Franceschini I, Caraty A, Carlton MBL, et al. 2007 Hypogonadotropic hypogonadism in mice lacking a functional Kiss1 gene. PNAS 104 10714-10719. (https://doi.org/10.1073/ pnas.0704114104)

De Croft S, Piet R, Mayer C, Mai O, Boehm U \& Herbison AE 2012 Spontaneous kisspeptin neuron firing in the adult mouse reveals marked sex and brain region differences but no support for a direct role in negative feedback. Endocrinology 153 5384-5393. (https://doi. org/10.1210/en.2012-1616) de Lacalle S 2006 Estrogen effects on neuronal morphology. Endocrine 29 185-190. (https://doi.org/10.1385/ENDO:29:2:185)

Desroziers E, Droguerre M, Bentsen AH, Robert V, Mikkelsen JD, Caraty A, Tillet Y, Duittoz A \& Franceschini I 2012 Embryonic development of kisspeptin neurones in rat. Journal of Neuroendocrinology 24 12841295. (https://doi.org/10.1111/j.1365-2826.2012.02333.x)

Franceschini I, Yeo SH, Beltramo M, Desroziers E, Okamura H, Herbison AE \& Caraty A 2013 Immunohistochemical evidence for the presence of various kisspeptin isoforms in the mammalian brain. Journal of Neuroendocrinology 25 839-851. (https://doi.org/10.1111/ jne.12069)

Gianetti E, Tusset C, Noel SD, Au MG, Dwyer AA, Hughes VA, Abreu AP, Carroll J, Trarbach E, Silveira LFG, et al. 2010 TAC3/TACR3 mutations reveal preferential activation of gonadotropin-releasing hormone release by neurokinin B in neonatal life followed by reversal in adulthood. Journal of Clinical Endocrinology and Metabolism 95 2857-2867. (https://doi.org/10.1210/jc.2009-2320)

Goldsmith PC \& Song T 1987 The gonadotropin releasing hormone containing ventral hypothalamic tract in the fetal rhesus monkey (Macaca mulatto). Journal of Comparative Neurology 257 130-139. (https://doi.org/10.1002/cne.902570110)

Gottsch ML, Popa SM, Lawhorn JK, Qiu J, Tonsfeldt KJ, Bosch MA, Kelly MJ, Rønnekleiv OK, Sanz E, McKnight GS, et al. 2011 Molecular properties of kiss1 neurons in the arcuate nucleus of the mouse. Endocrinology 152 4298-4309. (https://doi.org/10.1210/en.2011-1521)

Henderson RG, Brown AE \& Tobet SA 1999 Sex differences in cell migration in the preoptic area/anterior hypothalamus of mice. Journal of Neurobiology 41 252-266. (https://doi.org/10.1002/(SICI)10974695(19991105)41:2<252::AID-NEU8>3.0.CO;2-W)

Ho V, Yeo SY, Kunasegaran K, De Silva D, Tarulli GA, Voorhoeve PM \& Piettersen AM 2013 Expression analysis of rare cellular subsets : direct RT-PCR on limited cell numbers obtained by FACS or soft agar assays. BioTechniques 54 208-212. (https://doi.org/10.2144/000114019)

Hu MH, Li XF, McCausland B, Li SY, Gresham R, Kinsey-Jones JS, Gardiner JV, Sam AH, Bloom SR, Poston L, et al. 2015 Relative importance of the arcuate and anteroventral periventricular kisspeptin neurons in control of puberty and reproductive function in female rats. Endocrinology 156 2619-2631. (https://doi.org/10.1210/ en.2014-1655)

Jacobs DC, Veitch RE \& Chappell PE 2016 Evaluation of immortalized AVPV- and arcuate-specific neuronal kisspeptin cell lines to elucidate potential mechanisms of estrogen responsiveness and temporal gene expression in females. Endocrinology 157 3410-3419. (https://doi. org/10.1210/en.2016-1294)

Kauffman AS, Navarro VM, Kim J, Clifton DK \& Steiner RA 2009 Sex differences in the regulation of Kiss1/NKB neurons in juvenile mice: implications for the timing of puberty. American Journal of Physiology: Endocrinology and Metabolism 297 E1212-E1221. (https://doi. org/10.1152/ajpendo.00461.2009)

Knoll JG, Clay CM, Bouma GJ, Henion TR, Schwarting GA, Millar RP \& Tobet SA 2013 Developmental profile and sexually dimorphic expression of kiss1 and kiss1r in the fetal mouse brain. Frontiers in Endocrinology 4 140. (https://doi.org/10.3389/fendo.2013.00140)

Krajewski SJ, Burke MC, Anderson MJ, Mcmullen NT \& Rance NE 2010 Forebrain projections of arcuate neurokinin B neurons demonstrated by anterograde tract-tracing and monosodium glutamate lesions in the rat. Neuroscience 166 680-697. (https://doi.org/10.1016/j. neuroscience.2009.12.053)

Kumar D, Freese M, Drexler D, Hermans-Borgmeyer I, Marquardt A \& Boehm U 2014 Murine arcuate nucleus kisspeptin neurons communicate with GnRH neurons in utero. Journal of Neuroscience $\mathbf{3 4}$ 3756-3766. (https://doi.org/10.1523/JNEUROSCI.5123-13.2014)

Kumar D, Periasamy V, Freese M, Voigt A \& Boehm U 2015 In utero development of kisspeptin/GnRH neural circuitry in male mice. Endocrinology 156 3084-3090. (https://doi.org/10.1210/EN.20151412) https://joe.bioscientifica.com https://doi.org/10.1530/JOE-18-0142 (c) 2020 Society for Endocrinology Published by Bioscientifica Ltd. Printed in Great Britain 
Lehman MN, Hileman SM \& Goodman RL 2013 Neuroanatomy of the kisspeptin signaling system in mammals: comparative and developmental aspects. Advances in Experimental Medicine and Biology 784 27-62. (https://doi.org/10.1007/978-1-4614-6199-9_3)

Liu X \& Herbison AE 2016 Kisspeptin regulation of neuronal activity throughout the central nervous system. Endocrinology and Metabolism 31 193-205. (https://doi.org/10.3803/EnM.2016.31.2.193)

McCarthy MM 2008 Estradiol and the developing brain. Physiological Reviews 88 91-124. (https://doi.org/10.1152/physrev.00010.2007)

Mittelman-Smith MA, Krajewski-Hall SJ, McMullen NT \& Rance NE 2016 Ablation of KNDy neurons results in hypogonadotropic hypogonadism and amplifies the steroid-induced lh surge in female rats. Endocrinology 157 2015-2027. (https://doi.org/10.1210/en.20151740)

Navarro VM, Gottsch ML, Chavkin C, Okamura H, Clifton DK \& Steiner RA 2009 Regulation of gonadotropin-releasing hormone secretion by kisspeptin/dynorphin/neurokinin B neurons in the arcuate nucleus of the mouse. Journal of Neuroscience 29 11859-11866. (https://doi.org/10.1523/JNEUROSCI.1569-09.2009)

Navarro VM, Gottsch ML, Wu M, García-Galiano D, Hobbs SJ, Bosch MA Pinilla L, Clifton DK, Dearth A, Ronnekleiv OK, et al. 2011 Regulation of NKB pathways and their roles in the control of Kiss1 neurons in the arcuate nucleus of the male mouse. Endocrinology 152 4265-4275. (https://doi.org/10.1210/en.2011-1143)

Pointis G, Latreille MT \& Cedard L 1980 Gonado-pituitary relationships in the fetal mouse at various times during sexual differentiation. Journal of Endocrinology 86 483-488. (https://doi.org/10.1677/ joe.0.0860483)

Poling MC, Luo EY \& Kauffman AS 2017 Sex differences in steroid receptor coexpression and circadian-timed activation of kisspeptin and RFRP-3 neurons may contribute to the sexually dimorphic basis of the LH surge. Endocrinology 158 3565-3578. (https://doi. org/10.1210/en.2017-00405)
Rebuli ME \& Patisaul HB 2016 Assessment of sex specific endocrine disrupting effects in the prenatal and pre-pubertal rodent brain. Journal of Steroid Biochemistry and Molecular Biology 160 148-159. (https://doi.org/10.1016/j.jsbmb.2015.08.021)

Schambra U 2008 Prenatal Mouse Brain Atlas: Color Images and Annotated Diagrams of: Gestational Days 12, 14, 16 and 18 Sagittal, Coronal and Horizontal Section. Berlin, Germany: Springer Sciences and Business Media.

Smith JT, Cunningham MJ, Rissman EF, Clifton DK \& Steiner RA 2005a Regulation of Kiss1 gene expression in the brain of the female mouse. Endocrinology 146 3686-3692. (https://doi.org/10.1210/en.2005-0488)

Smith JT, Dungan HM, Stoll EA, Gottsch ML, Braun RE, Eacker SM, Clifton DK \& Steiner RA 2005 $b$ Differential regulation of KiSS-1 mRNA expression by sex steroids in the brain of the male mouse. Endocrinology 146 2976-2984. (https://doi.org/10.1210/en.2005-0323)

Treen AK, Luo V, Chalmers JA, Dalvi PS, Tran D, Ye W, Kim GL, Friedman Z \& Belsham DD 2016 Divergent regulation of ER and Kiss genes by $17 \beta$-estradiol in hypothalamic ARC versus AVPV models. Molecular Endocrinology 30 217-233. (https://doi.org/10.1210/ me.2015-1189)

Wolfe CA, Van Doren M, Walker HJ, Seney ML, McClellan KM \& Tobet SA 2005 Sex differences in the location of immunochemically defined cell populations in the mouse preoptic area/anterior hypothalamus. Brain Research: Developmental Brain Research 157 34-41. (https://doi. org/10.1016/j.devbrainres.2005.03.001)

Yip SH, Boehm U, Herbison AE \& Campbell RE 2015 Conditional viral tract-tracing delineates the projections of the distinct kisspeptin neuron populations to gonadotropin-releasing hormone $(\mathrm{GnRH})$ neurons in the mouse. Endocrinology 156 2582-2594. (https://doi. org/10.1210/en.2015-1131)

Young WJ \& Chang C 1998 Ontogeny and autoregulation of androgen receptor mRNA expression in the nervous system. Endocrine 9 79-88. (https://doi.org/10.1385/ENDO:9:1:79)

Received in final form 25 October 2019

Accepted 31 October 2019

Accepted Manuscript published online 31 October 2019 (c) 2020 Society for Endocrinology Published by Bioscientifica Ltd. Printed in Great Britain 